\title{
Craniopharyngioma in the third ventricle: necropsy findings and histogenesis
}

\author{
KATSUZO KUNISHIO, YUJI YAMAMOTO, NORIO SUNAMI, SHOJI ASARI, \\ TADAATSU AKAGI,* YUJI OHTSUKI* \\ From the Department of Neurological Surgery, Matsuyama Shimin Hospital, Ehime and Department of \\ Pathology, ${ }^{*}$ Kochi Medical School, Kochi, Japan
}

SUMMARY A case of craniopharyngioma confined within the third ventricle with necropsy is reported. A stalk-like structure in this tumour was present in the wall of the third ventricle at its base. It is suggested that this tumour might have arisen from the remnants of Rathke's pouch persisting in the tuber cinereum.

Craniopharyngiomas have been considered to be derived from remnants of Rathke's pouch, which is thought to lie in the superior aspect of the pituitary stalk and infundibulum. They commonly occupy the suprasellar cistern and may occasionally spread into the anterior, middle, or posterior cranial fossae, as well as into the sella turcica. Craniopharyngioma confined to the third ventricle, however, is rare. Only six necropsy cases ${ }^{1-5}$ have been so far reported. In this paper, the origin of craniopharyngioma confined to the third ventricle is discussed based on the findings of a necropsy case.

\section{Case report}

A 49 year old man was admitted because of progressive memory defect and general malaise of three months' duration. He was of normal stature and slightly malnourished. The distribution and texture of the axillary and pubic hair were normal. He was apathetic and disoriented to time and place. Other physical and neurological findings were normal.

Routine blood studies, urinalysis and endocrinological work-up revealed no abnormalities, and there was no diabetes insipidus. Plain radiographs of the skull were normal. Cerebral angiography demonstrated lateral displacement of the insular portion of the middle cerebral arteries, lenticulostriate arteries and thalamostriate veins, which suggested internal hydrocephalus, and revealed some tumour stain in the third ventricle. Precontrast axial CT showed an isodense

Address for reprint requests: Katsuzo Kunishio, MD. Department of Neurological Surgery, Matsuyama Shimin Hospital, 2-6-5 Ohtemachi, Matsuyama, Ehime 790, Japan.

Received 21 March 1986 and in revised form 20 August 1986. Accepted 30 August 1986 or slightly low-density mass (mean Hounsfield units (HU): 30) occupying the third ventricle, and the lateral ventricles were dilated. With contrast medium there was homogeneous enhancement (mean HU: 68) of the entire mass situated in the third ventricle. Coronal CT scans showed that an enhanced mass seemed to be separated from the sella turcica and confined to the third ventricle. Conray ventriculography showed a large mass almost completely filling the anterior part of the third ventricle. A static technetium $99^{\mathrm{m}}$ brain scan revealed no increased up-take. An electroencephalogram showed bifrontal slow wave activity.

The patient underwent a right frontal craniotomy. The tumour was partially removed by a transcallosal approach using an operating microscope. The orange, grained surface of the tumour was seen projecting through the dilated foramen of Monro. The solid, soft tumour was partially removed piecemeal because it was wedged into the third ventricle very tightly. It was verified histologically as squamous cell type craniopharyngioma.

After the operation he recovered well and became oriented, but his consciousness began to cloud from 20 hours after the operation, and he suddenly fell into a coma. CT scans showed acute brain swelling with intracerebral hematoma in the right frontal lobe. Emergency right frontal lobectomy with external decompression was performed. Two weeks later, a ventriculoperitoneal shunt was inserted, but he did not regain consciousness completely. He died five months after the first operation.

\section{Postmortem examination}

Gross findings. The brain weighed $1600 \mathrm{~g}$. At the base of the brain, the tumour was not visible even around the optic chiasm and pituitary stalk. The hypothalamus and tuber cinereum at the base of the brain protruded because of the compression by the tumour mass which could be observed in the third ventricle through the arachnoid membrane over the tuber cinereum. The cut surface of the brain disclosed the 
Fig 1 Coronal section through the basal ganglia and optic chiasm, showing the tumour within the third ventricle. T: tumour.
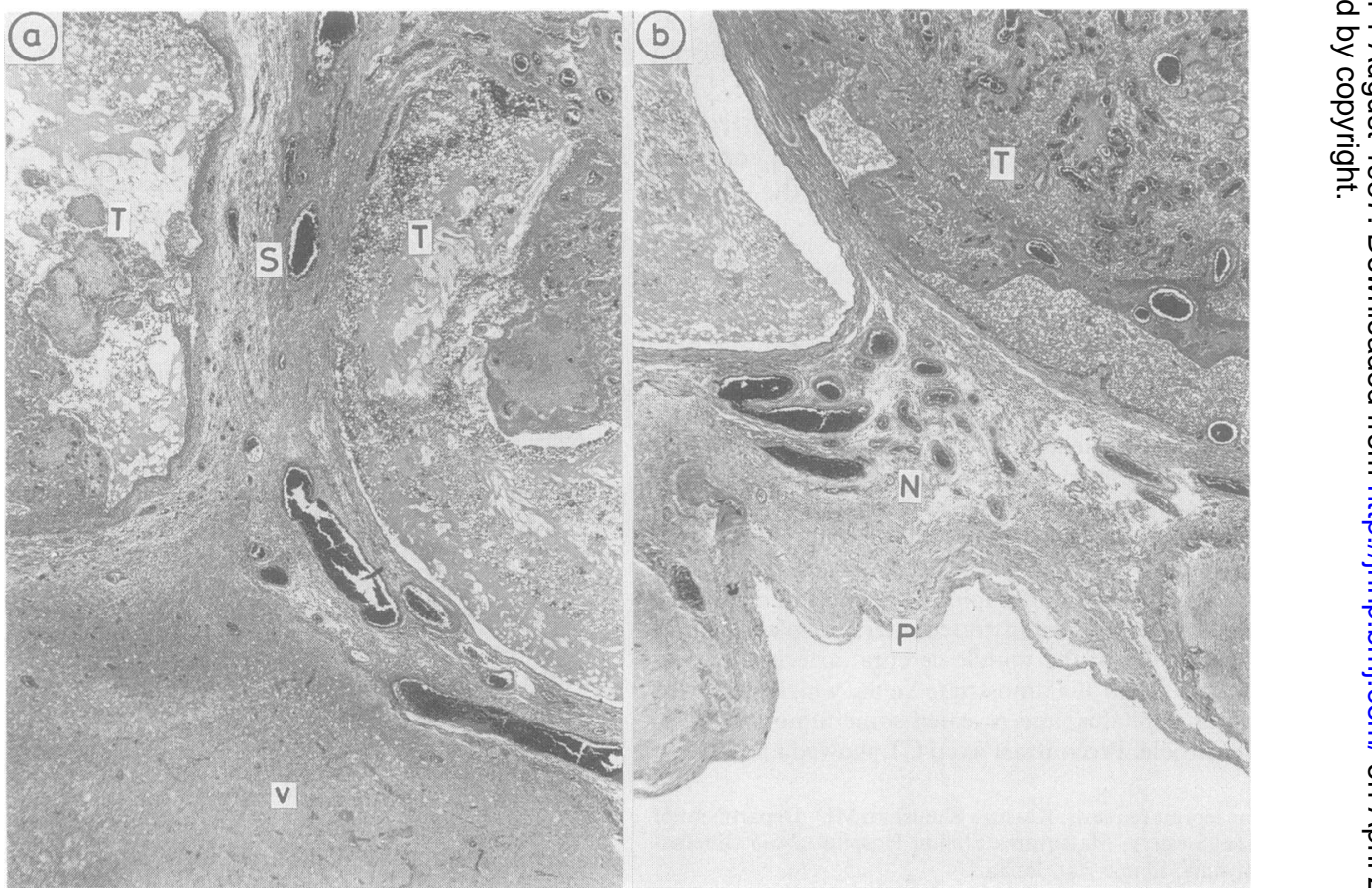

Fig 2 (a) Photomicrograph of the stalk-like structure involving the brain tissue of the ventricular wall.

$(H \& E \times 20)$. T: tumour, V: ventricular wall, S: stalk-like structure. (b) Photomicrograph of the base of the third ventricle, showing the intervention of thin neural tissue between the tumour and pia mater.

(H\&E $\times 20)$. T: tumour, $N$ : neural tissue, $P$ : pia mater. 
dark reddish or greywhitish tumour with a granular surface $(3.5 \times 4.9 \times 3.0 \mathrm{~cm}$ in size) exclusively growing in the third ventricle, and the border of the tumour was distinct (fig 1). A stalk-like structure, from which this tumour appeared to develop, was detected in the wall of the third ventricle at the coronal section of the tumour at $5 \mathrm{~mm}$ posterior to the optic chiasm. In the midbrain, massive bleeding and parenchymal destruction, which were considered as the direct cause of death, were induced by the compression from the expanding tumour.

Microscopic findings The sharply demarcated tumour within the third ventricle was composed of irregularly branched solid nests and papillary growth of tumour cells, and relatively scanty stroma of fibrous connective tissue associated with capillaries. The tumour cells showed a pavement-like arrangement, revealing conspicuous intercellular bridges and small keratinising foci in parts, characteristic of squamous cells. The third ventricular wall was covered by multilayered tumour cells, and a fine papillary pattern composed of the same kind of cells was found at the free surface of the tumour. Arrangements of monolayered cuboidal cells around stroma formed adamantinomatous patterns. A stalk-like extension of this tumour, involving the brain tissue in the ventricular wall, was detected in the base of the third ventricle, which corresponded to the tuber cinereum, and this tumour proliferated exclusively into the cavity of the third ventricle (fig 2a). Histologically, at the base of the third ventricle, the tumour did not extend to the brain surface, and thin neural tissue was observed between the tumour and pia mater (fig 2b). No squamous epithelial nest was observed in the tuber cinereum or infundibulum. Neither tumour nor squamous epithelial nest was observed in the serial sections of the pituitary stalk.

\section{Discussion}

Craniopharyngiomas usually arise from squamous epithelial nests in the pars tuberalis along the pituitary stalk. ${ }^{6}$ Luse and Kernohan ${ }^{7}$ reviewed 1,364 pituitary glands, and in none of 78 patients less than 10 years of age at the time of death were squamous epithelial nests identified, although craniopharyngiomas are relatively frequently encountered in this age group. Therefore, they thought that these squamous epithelial nests were secondary to metaplasia of the cells of the pars tuberalis rather than embryonic nests. On the other hand, Goldberg and Eshbaugh ${ }^{8}$ found squamous epithelial nests in the pituitaries of four newborn infants $(3 \%)$. They stated that the presence of squamous epithelial nests in the pituitaries of newborn infants was in favour of their being remnants of Rathke's pouch, and that the apparent absence of squamous epithelial nests in infants was due to their incomplete differentiation at that time of life. There are thus two theories on the histogenesis of squamous epithelial nests, but the one stating the origin as the remnants of Rathke's pouch is more generally accepted. In either case, squamous epithelial nests are considered to be derived from the cells of the pars tuberalis. Atwell ${ }^{9}$ maintained that the pars tuberalis grew forward and backward, surrounding the infundibulum and spreading out under the tuber cinereum. From this point of view, it may be possible that craniopharyngiomas arising from squamous epithelial nests of the pars tuberalis grow incidentally and exclusively in the third ventricle.

To our knowledge, only six necropsy cases ${ }^{1-5}$ of craniopharyngioma located entirely within the third ventricle have been reported to date. In 1953, Dobos et al, ${ }^{1}$ reported an intrinsic tumour of the third ventricle that was probably a craniopharyngioma and mentioned that this arose from the infundibulum, so that a designation such as "infundibuloepithelioma" would appear more correct. Cashion and Young ${ }^{2}$ did not believe that there were any significant histological features that differentiated intraventricular craniopharyngioma from those in other locations, but did not discuss the origin of intraventricular craniopharyngioma. Namba and $\mathrm{Tsuboi}^{4}$ found tumour cells of the squamous type in a tumour of the third ventricle showing direct continuity with the pituitary stalk. They concluded that the tumour, histologically craniopharyngioma, arose from the remnants of Rathke's pouch and grew into the third ventricular cavity. Kubota et $a^{5}$ reported that the squamous epithelial nests were detected in the pituitary stalk and the tuber cinereum, which extended upward and showed a gradual transition to tumour tissue in the third ventricle, and that these findings seemed to suggest the metaplastic squamous epithelial nests as the origin of the tumour. On the other hand, as for the development of the pars tuberalis, which was generally considered as the origin of craniopharyngioma, it was demonstrated that the cells of the pars tuberalis could migrate not only to the anterior part, but also the posterior part of the hypophysis and extend to the infundibulum and tuber cinereum.

In our case, the tumour possessed a stalk-like structure located at the base of the third ventricle near the tuber cinereum. No tumour cells were found in the pituitary stalk. In addition, this tumour was covered by the pia mater and a thin layer of neural tissue and did not extend to the surface of the brain. Therefore, it might be concluded that this tumour was derived from the cells that had migrated from the pars tuberalis as the remnants of Rathke's pouch, which had been present in part of the stalk-like structure at the base of the third ventricle, and grew incidentally and exclusively into the third ventricular cavity.

\section{References}

1 Dobos EI, Freed CG, Ashe SMP. An intrinsic tumor of the third ventricle. J Neuropathol Exp Neurol 1953; 12:232-43. 
2 Cashion EL, Young JM. Craniopharyngioma in the third ventricle. J Jenn Med Ass 1962;55:156-60.

3 Cashion EL, Young JM. Intraventricular craniopharyngioma. Report of two cases. $J$ Neurosurg 1971;34:84-7.

4 Namba S, Tsuboi M. Craniopharyngioma in the third ventricle. No To Shinkei 1977;29:865-9.

5 Kubota T, Fujii H, Ikeda $\mathrm{K}$, Ito $\mathrm{H}$, Yamamoto $\mathrm{S}$, Nakanishi I. A case of intraventricular cranio- pharyngioma with subarachnoid hemorrhage. No Shinkei Geka 1980;8:495-501.

6 Russell DS, Rubinstein JL. Pathology of Tumors of the Nervous System. 4th ed. Edward Arnold Ltd, 1977.

7 Luse SA, Kernohan JW. Squamous-cell nests of the pituitary gland. Cancer 1955;8:623-8.

8 Goldberg GM, Eshbaugh DE. Squamous cell nests of the pituitary gland as related to the origin of craniopharyngiomas. Arch Pathol 1960;70:293-9. 